\title{
Observational Study of Saroglitazar on Metabolic Parameters in Indian Patients with Diabetic Dyslipidaemia - A Fifty Eight Weeks of Clinical Experience
}

\author{
Chatterjee $\mathrm{S}^{1 *}$, Majumder $\mathrm{A}^{2}$, Ray $\mathrm{S}^{1}$ and Bhattacharjee $\mathrm{K}^{3}$ \\ ${ }^{1}$ Apollo Gleneagles Hospital, Kolkata, India \\ ${ }^{2}$ KPC Medical College, Kolkata, India \\ ${ }^{3} \mathrm{PhD}$ Scholar, JJT University, India
}

Research Article

Volume 3 Issue 2

Received Date: May 15, 2018

Published Date: May 25, 2018

*Corresponding author: Sanjay Chatterjee, MD Consultant Diabetologist, Apollo Gleneagles Hospital, 58 Canal Circular Road, Kolkata 700054, India, Tel: +91 33 23203040; Email: Sanjay_doc@yahoo.co.in

\section{Abstract}

Background: Earlier we had reported results of our study of treatment with Saroglitazar, in a dose of 4 mg daily, for 14 weeks in 34 patients with diabetic dyslipidemia., and showed significant improvement in both glycemic and lipid parameters. We conducted this 58 weeks follow-up study in 158 patients to determine whether the improvement in glycemic and lipid parameters persisted in long-term follow-up and whether long-term therapy had any effect on the blood pressure, weight, renal and liver functions.

Methods: We have studied follow-up data of 158 patients collected from the authors' clinic databases and analyzed the effect of saroglitazar on metabolic parameters. Data of patients having both baseline and follow-up data were included in the analysis. The mean duration of follow-up was 58 weeks. Saroglitazar was prescribed at a dose of $4 \mathrm{mg}$ daily, in accordance with approved indication and prescribing information, to patients of T2DM and having hypertriglyceridemia (serum TG level $\geq 150 \mathrm{mg} / \mathrm{dl}$ ). Patients received treatment as per routine standard of care without any experimentation on any patient. The patients' physical parameters (weight, blood pressure etc.), serum lipid profile and glycemic parameters (fasting plasma glucose, post-meal plasma glucose,HbA1C) were determined at baseline and at last follow-up visit.

Results: After a mean study duration period of 58 weeks of 158 patients with diabetic dyslipidemia, there was significant reduction in triglycerides from $319.88 \pm 178.75 \mathrm{mg} / \mathrm{dl}($ mean $\pm \mathrm{SD}$ ) to $174.03 \pm 113.62 \mathrm{mg} / \mathrm{dl}$ (reduction of $145.84 \pm$ $186.59 \mathrm{mg} / \mathrm{dl} ; \mathrm{p}<0.001$ ). Glycosylated hemoglobin (HbA1c) was reduced from $7.91 \pm 1.53 \%$ (mean $\pm \mathrm{SD}$ ) to $7.25 \pm 1.38 \%$ (reduction of $0.65 \pm 1.37 \%$; $<<0.001$ ). Other lipid and glycemic parameters such as total cholesterol, low-density 


\section{Diabetes and Obesity International Journal}

lipoprotein, non-high-density lipoprotein, triglyceride/HDLc ratio, fasting and postprandial plasma glucose were also significantly reduced. There were no major adverse events observed or, reported during the entire study period.

Conclusion: Our long-term follow-up study showed that dual PPAR $\alpha+\gamma$ agonist, saroglitazar, could be an effective and safe therapeutic option in adult patients with diabetic dyslipidemia with a persistent and significant improvement in glycemic and lipid parameters and may confer an additional beneficial effect on blood pressure and liver function as well.

Keywords: Saroglitazar; Diabetic Dyslipidemia; India; Real World

\section{Significant Findings of the Study}

The significant improvements in glycemic and lipid parameters persisted even in long-term in a larger sample size with an additional benefit on blood pressure and liver function without any adverse effect on renal function, thereby demonstrating the efficacy and safety of the dual PPAR $\alpha+\gamma$ agonist, saroglitazar.

\section{What this Study Adds}

The current study is a long term follow up and establishing for the first time the 58 weeks clinical safety and efficacy of Saroglitazar $4 \mathrm{mg}$ once daily in patients with diabetes and hypertriglyceridemia in a real world scenario.

\section{Introduction}

Type 2 Diabetes Mellitus (T2DM) is a major global health burden affecting millions across the globe leading to various complications causing cardiovascular morbidity and mortality. Dyslipidaemia is an important risk factor for cardiovascular diseases (CVD) found to be inherently associated with diabetes.

Diabetic dyslipidaemia (DD) is a particular laboratory phenotype of the lipid profile observed in patients with T2DM: hypertriglyceridaemia with low serum highdensity lipoprotein cholesterol (HDLc) concentrations, normal or, moderately elevated serum low-density lipoprotein (LDLc) levels with increased small dense LDL (sdLDL) particles [1-3]. The prevalence of DD reported in various studies varied between 35 and $50 \%$ and is strongly associated with increased cardiovascular risk [4].

Despite statin therapy and LDL-lowering, a residual risk of cardiovascular events still persists in all patients.
Nevertheless, the residual CVD risk is especially higher in patients with diabetes as demonstrated in an analysis by the collaborators of the Cholesterol Treatment Trialists' (CTT) [5]. Several genome-wide association studies indicate an independent causal role of triglyceride (TG)rich lipoproteins (TRL) in CVD [6-8]. Additionally, severe hypertriglyceridaemia is associated with an increased risk of acute pancreatitis [9]. Some international guidelines recommend treatment of TG at levels more than 200 $\mathrm{mg} / \mathrm{dl}$ despite the use of high-intensity statin therapy [10]. The current treatment options available for reducing hypertriglyceridaemia are fibrates, niacin, long chain omega 3 fatty acids and saroglitazar.

Saroglitazar is approved in India for treating hypertriglyceridaemia in patients with diabetes and it has a potential role in reducing both lipid and glycaemic parameters being a dual $(\alpha+\gamma)$ peroxisome proliferatoractivated receptor (PPAR) agonist. Phase III, controlled clinical trials have shown that saroglitazar $4 \mathrm{mg}$ once daily, when added to statin, leads to significant decrease in triglyceride (45-46.7\%) and non HDLc $(32.5 \%)$ and resulted in significant decrease in $\mathrm{HbA1c}(0.3 \%)[11,12]$.

This study was aimed at evaluating effectiveness and safety of Saroglitazar in real time clinical settings. We had earlier reported, the use of saroglitazar on patients with diabetic dyslipidemia and observed significant changes in both lipid and glycemic parameters [13]. This study is an extension of our earlier observation on more number of patients and with more prolonged duration of treatment.

\section{Methods}

Saroglitazar was prescribed at a dose of $4 \mathrm{mg}$ daily, as per the approved indication and prescribing information, to patients of T2DM and having hypertriglyceridemia (serum TG level $\geq 150 \mathrm{mg} / \mathrm{dl}$ ). Patients received treatment 


\section{Diabetes and Obesity International Journal}

as per routine standard of care without any experimentation on any patient. Data of only those patients were considered for final evaluation having both baseline and follow-up values of fasting plasma glucose, post-prandial plasma glucose, glycated hemoglobin (HbA1c) and lipid profile. A total of 158 patients' data analyzed for study. Out of 158 patients, 118 patients received statins. Patients' data was collected from the authors' clinic databases.

The patients' physical parameters (weight, blood pressure etc.), serum lipid profile and glycaemic parameters (fasting plasma glucose, post-meal plasma glucose,HbA1c) were determined at baseline and at last follow-up visit. Descriptive data analytics has been carried out in the present study. Results on continuous measurements are presented as mean \pm SD and results on categorical measurements are represented in counts (\%). Significance is assessed at a level of $5 \%$.

Normality of data was tested by simultaneous Anderson Darling test, Shapiro-Wilk test and graphically by QQ plot. Paired t-test was applied to detectany significance change of study parameters measured on two occasions for same group of patients. A p value of $<0.05$ was considered as statistically significant.

\section{Ethical Approval}

The current study was a retrospective study retrieving and analyzing data from author's clinic database. All the included patients received treatment as per approved guidelines of regulatory authorities without any experimentation on any patient. The identity of none of the patients was disclosed at any place of the manuscript and patients' confidentiality was not compromised. Hence, all the authors felt that Approval of Ethics Committee is not necessary and also Informed Consent was not necessary.

\section{Statistical Software}

The Statistical software namely SAS (Statistical Analysis System) version 9.2 for windows, SAS Institute Inc. Cary, NC, USA and Statistical Package for Social Sciences (SPSS Complex Samples) Version 21.0 for windows, SPSS, Inc., Chicago, IL, USA were used for the analysis of the data. Microsoft word 2010 and Microsoft Excel 2010 (Microsoft Corp, Redmond, WA, USA), have been used to generate graphs and tables.

\section{Results}

A total of 158 patients' data was analyzed in this observational study, which had a male preponderance (67.72\% males versus $32.28 \%$ females). The mean age was $51.34 \pm 10.87$ years and average weight was $70.52 \pm$ 2.13 kgs (Table 2). All were T2DM patients and had dyslipidemia (TG>150 mg/dl). A total of $53.16 \%$ patients were overweight/ obese and $58.86 \%$ patients were hypertensive. Other significant co-morbidities are enlisted in Table 1. Baseline parameters of patients are documented in Table 2.

\begin{tabular}{|c|c|c|}
\hline Comorbidities & Number (n) & Percentage (\%) \\
\hline Overweight/Obesity & 84 & 53.16 \\
\hline Hypertension & 93 & 58.86 \\
\hline Microalbuminuria & 35 & 22.15 \\
\hline Diabetic Nephropathy & 9 & 5.7 \\
\hline CHD & 8 & 5.06 \\
\hline Hypothyroidism & 15 & 9.49 \\
\hline Fatty Liver(by USG) & 14 & 8.86 \\
\hline Statin Usage & 118 & 74.68 \\
\hline $\begin{array}{c}\text { Alteration in } \\
\text { Medication }\end{array}$ & 101 & 63.92 \\
\hline
\end{tabular}

Table 1: Comorbidities ( $\mathrm{N}=158)$.

\begin{tabular}{|c|c|}
\hline \multicolumn{2}{|c|}{ Demographic Profile, N=158 } \\
\hline Male(number) & 107 \\
\hline Female(number) & 51 \\
\hline Age, Mean \pm SD (years) & $51.34 \pm 10.87$ \\
\hline Weight, Mean \pm SD (Kgs) & $70.52 \pm 2.13$ \\
\hline SBP, Mean \pm SD (mmHg) & $131.24 \pm 12.2$ \\
\hline DBP, Mean \pm SD (mmHg) & $80.79 \pm 7.02$ \\
\hline \multicolumn{2}{|c|}{ Laboratory data } \\
\hline FPG, Mean \pm SD(mg/dL) & $160.31 \pm 58.3$ \\
\hline PPPG, Mean \pm SD(mg/dL) & $234.93 \pm 94.3$ \\
\hline HbA1c, Mean \pm SD (\%) & $7.98 \pm 1.58$ \\
\hline Total Cholesterol, Mean \pm & $180.67 \pm 50.94$ \\
SD(mg/dL) & $315.4 \pm 176.31$ \\
\hline Triglycerides, Mean \pm SD(mg/dL) & $38.38 \pm 10.17$ \\
\hline HDL, Mean \pm SD(mg/dL) & $101.77 \pm 41.91$ \\
\hline LDL, Mean \pm SD(mg/dL) & $139.52 \pm 56.28$ \\
\hline Non-HDL, Mean \pm SD(mg/dL) & $8.28 \pm 5.15$ \\
\hline TG/HDL ratio, Mean \pm SD & $42.15 \pm 26.62$ \\
\hline ALT, Mean \pm SD(IU/L) & $0.98 \pm 0.29$ \\
\hline Serum Creatinine, Mean \pm \\
SD(mg/dL)
\end{tabular}

Table 2: Baseline characteristics. 


\section{Diabetes and Obesity International Journal}

After 58 weeks, the mean blood pressure was significantly reduced, both systolic $(\mathrm{P}=0.004)$ and

diastolic ( $\mathrm{P}=0.001)$ (Table 3).

Mean follow-up period (14 weeks) in 34 patients [Ref:13] Mean follow-up period (58 weeks) in 158 patients

\begin{tabular}{|c|c|c|c|c|c|c|c|c|}
\hline Parameters & $\begin{array}{c}\text { Baseline } \\
\text { values }\end{array}$ & At Follow up & $\begin{array}{c}\text { Mean } \\
\text { change }\end{array}$ & $\begin{array}{c}\text { P value (two- } \\
\text { tailed) }\end{array}$ & $\begin{array}{c}\text { Baseline } \\
\text { values }\end{array}$ & At Follow up & $\begin{array}{l}\text { Mean } \\
\text { change }\end{array}$ & $\begin{array}{c}\text { P value } \\
\text { (two- } \\
\text { tailed) }\end{array}$ \\
\hline $\begin{array}{c}\text { Weight, Mean } \\
\pm \text { SD (Kgs) } \\
\end{array}$ & $69.14 \pm 9.56$ & $69.85 \pm 10.52$ & $+0.71 \pm 0.78$ & 0.07 & $70.61 \pm 12.13$ & $71.69 \pm 12.93$ & $\begin{array}{c}1.09 \pm \\
4.40 \\
\end{array}$ & 0.002 \\
\hline $\begin{array}{c}\text { SBP, } \\
\text { Mean } \pm \text { SD } \\
(\mathrm{mmHg})\end{array}$ & $\begin{array}{c}131.70 \pm \\
14.81\end{array}$ & $\begin{array}{c}127.77 \pm \\
10.71\end{array}$ & $-4.35 \pm 4.20$ & 0.06 & $131.24 \pm 12.2$ & $127.13 \pm 17.53$ & $\begin{array}{l}-4.21 \pm \\
17.70\end{array}$ & 0.004 \\
\hline $\begin{array}{c}\text { DBP, } \\
\text { Mean } \pm \text { SD } \\
(\mathrm{mmHg})\end{array}$ & $80.67 \pm 5.94$ & $79.00 \pm 4.87$ & $-1.39 \pm 0.54$ & 0.2 & $80.79 \pm 7.02$ & $79.03 \pm 5.76$ & $\begin{array}{l}-1.76 \pm \\
6.68\end{array}$ & 0.001 \\
\hline
\end{tabular}

Table 3: Effect of saroglitazar on Physical Parameters.

After the completion of 58 weeks mean follow-up, HbA1c was significantly reduced $(\mathrm{P}<0.001)$ from $7.91 \%$ to $7.25 \%$.The other glycaemic parameters namely fasting plasma glucose and post prandial plasma glucose were also significantly reduced $(\mathrm{P}<0.001)$ (Table 4$)$.

The addition of saroglitazar favorably modified the lipid profile of the patients, regardless of concomitant statin therapy. Serum triglycerides level was significantly reduced from $319.88 \mathrm{mg} / \mathrm{dl}$ at baseline to $174.03 \mathrm{mg} / \mathrm{dl}$ at 58 week follow up $(\mathrm{P}<0.001)$. All of the other lipid parameters such as total cholesterol (TC), LDLc, nonHDLc and triglyceride/HDLc ratio were significantly reduced after 58 weeks of Saroglitazar therapy. The substantial drop in non-HDLc level in our study may have a favorable effect on residual CV risk-reduction with addition of Saroglitazar therapy. Mean HDLc increased, however the values were not significant (Table 4). Another interesting finding of the present study is the robust decrease in triglyceride/HDLc ratio, and this may have a well-disposed effect on LDL particle size. The LDL particle size is better indicated by TG/HDL ratio than triglyceride level. A reduction of both triglyceride and TG/HDL ratio makes a shift of the small dense LDL particles to more buoyant and larger LDL particles which are less atherogenic [13].

\begin{tabular}{|c|c|c|c|c|c|c|c|c|}
\hline \multicolumn{5}{|c|}{ Mean follow-up period (34 weeks) ${ }^{[R e f: 13]}$} & \multicolumn{4}{|c|}{ Mean follow-up period (58 weeks) } \\
\hline Parameters & $\begin{array}{c}\text { Baseline } \\
\text { values }\end{array}$ & $\begin{array}{c}\text { At Follow- } \\
\text { up }\end{array}$ & $\begin{array}{l}\text { Mean } \\
\text { change }\end{array}$ & $P$ value & Baseline vi & At Follow- up & Mean change & P value \\
\hline $\begin{array}{r}\text { FPG N } \\
(\mathrm{m}\end{array}$ & & & & 0 & $60.46 \pm 58.37$ & $134.67 \pm 45.51$ & -25.7 & $<0.001$ \\
\hline $\begin{array}{r}\text { PPPG Mea } \\
(\mathrm{mg} / \mathrm{c}\end{array}$ & $\begin{array}{c}243.68 \pm \\
114.59 \\
\end{array}$ & $\begin{array}{c}177.39 \pm \\
60.87 \\
\end{array}$ & $\begin{array}{c}-66.29 \pm \\
34.71\end{array}$ & & $35.42 \pm 95.05$ & $191.55 \pm 66.52$ & -43.87 & $<0.001$ \\
\hline $\begin{array}{r}\text { HbA1c Me } \\
(\%\end{array}$ & 8 & 33. & 1 & & & & & 1 \\
\hline $\begin{array}{r}\text { Choleste } \\
\pm \text { SD ( } \\
\end{array}$ & $\begin{array}{r}195 . \\
56 \\
\end{array}$ & $\begin{array}{c}147.75 \pm \\
36.08 \\
\end{array}$ & $\begin{array}{r}-48 \\
17 \\
\end{array}$ & & 0 & 55 & -32.61 & $<0.001$ \\
\hline $\begin{array}{c}\text { Triglyc } \\
\text { Mean } \\
\text { (mg) }\end{array}$ & $\begin{array}{c}346.78 \pm \\
246.01\end{array}$ & $\begin{array}{c}154.00 \pm \\
127.73\end{array}$ & $\begin{array}{l}-192.78 \\
\pm 91.06\end{array}$ & & 75 & & $\begin{array}{r}-14 \\
18\end{array}$ & 0.001 \\
\hline $\begin{array}{c}\text { HDL-C Mean } \pm \text { SD } \\
(\mathrm{mg} / \mathrm{dL})\end{array}$ & $\beta 8.88 \pm 9.79$ & $\begin{array}{c}39.34 \pm \\
11.37\end{array}$ & $\begin{array}{r}+0 . \\
3 .\end{array}$ & & & & & 0.69 \\
\hline $\begin{array}{c}\text { LDL-C Mean } \pm \text { SD } \\
(\mathrm{mg} / \mathrm{dL})\end{array}$ & $\begin{array}{c}108.34 \pm \\
46.94\end{array}$ & $\begin{array}{l}84.31 \pm \\
23.26\end{array}$ & $\begin{array}{c}-24.04 \pm \\
16.14\end{array}$ & & & 38 & & 6 \\
\hline Non HDL-C Mean & $157.34 \pm$ & $108.63 \pm$ & $-48.72 \pm$ & $<0.0001$ & $140.14 \pm 55.4$ & $104.52 \pm 49.7$ & $-35.63 \pm 58.99$ & $<0.001$ \\
\hline
\end{tabular}




\section{Diabetes and Obesity International Journal}

\begin{tabular}{|c|c|c|c|c|c|c|c|c|}
\hline \pm SD (mg/dL) & 53.44 & 34.47 & 17.09 & & & & & \\
\hline TG/HDL-C Mean \pm \\
SD (mg/dL)
\end{tabular}

Table 4: Effect of saroglitazar on Metabolic Parameters.

Saroglitazar was found to be safe with no major adverse events reported throughout the entire duration of 58 weeks. Liver enzymes ALT and AST were both reduced from baseline, the ALT reduction being significant $(\mathrm{P}<0.001)$. Serum creatinine was not adversely affected during this observational study (Table 5).

\begin{tabular}{|c|c|c|c|c|c|c|c|c|}
\hline \multicolumn{2}{|c|}{ Mean follow-up period (34 weeks) [Ref:13] } & \multicolumn{5}{c|}{ Mean follow-up period (58 weeks) } \\
\hline Parameters & $\begin{array}{c}\text { Baseline } \\
\text { values }\end{array}$ & $\begin{array}{c}\text { At Follow- } \\
\text { up }\end{array}$ & $\begin{array}{c}\text { Mean } \\
\text { change }\end{array}$ & P value & $\begin{array}{c}\text { Baseline } \\
\text { values }\end{array}$ & At Follow-up & Mean change & P value \\
\hline $\begin{array}{c}\text { AST Mean } \pm \text { SD } \\
\text { (U/L) }\end{array}$ & \multicolumn{3}{|c|}{ Not Captured in previous Study } & $31.63 \pm 17.11$ & $27.63 \pm 10.35$ & $-4.00 \pm 15.54$ & 0.15 \\
\hline $\begin{array}{c}\text { ALT Mean } \pm \text { SD } \\
\text { (U/L) }\end{array}$ & $\begin{array}{c}52.83 \pm \\
31.96\end{array}$ & $\begin{array}{c}43.17 \pm \\
27.84\end{array}$ & $\begin{array}{c}-9.69 \pm \\
9.05\end{array}$ & 0.03 & $42.15 \pm 26.62$ & $30.19 \pm 20.36$ & $-12.64 \pm 27.34$ & $<0.001$ \\
\hline $\begin{array}{c}\text { rreatinine Mean } \\
\text { SD (mg/dL) }\end{array}$ & $0.95 \pm 0.21$ & $1.04 \pm 0.24$ & $\begin{array}{c}0.098 \pm \\
0.10\end{array}$ & 0.06 & $0.98 \pm 0.29$ & $1.00 \pm 0.29$ & $0.022 \pm 0.18$ & 0.20 \\
\hline
\end{tabular}

$\mathrm{P}<0.05$ considered as statistically significant

Table 5: Safety and Tolerability of saroglitazar.

\section{Discussion}

Elevated plasma TG (TG $>150 \mathrm{mg} / \mathrm{dl})$ and non-HDLc levels have been found to be independently associated with increased cardiovascular disease (CVD) risk and severe hypertriglyceridaemia (TG>500 mg/dl) have been associated with an increased risk of acute pancreatitis $[14,15]$. Likewise, latest consensus statement by American Association of Clinical Endocrinologists and American College of Endocrinology (AACE/ACE) advocates reducing triglyceride levels when severely elevated $(>500 \mathrm{mg} / \mathrm{dL})$ to prevent pancreatitis [16]. While no large clinical trials have been designed to test this objective, observational data and retrospective analyses support long term dietary and lipid management of hypertriglyceridaemia for prophylaxis against or treatment of acute pancreatitis [16].

Theoretically, Non-high-density lipoprotein cholesterol (non-HDLc) level poses to be an important predictor of coronary heart disease (CHD) risk than LDLc for it comprehensively corresponds to total cholesterol carried in all potentially atherogenic lipoprotein particles namely low-density lipoprotein (LDL), very low density lipoprotein (VLDL), VLDL remnants, intermediate-density lipoprotein (IDL), and lipoprotein(a) . To investigate the same, Cui and associates examined the data obtained from the Lipid Research Clinics (LRC) Program Follow-up Study, whether the non-HDLc level would predict cardiovascular disease (CVD) mortality, and how it equates to LDLc in this prediction. A total of 4,462 men and women, who were followed up for 19 years in the LRC Program Follow-up Study, were analyzed for CVD death. The CVD mortality (both in men and women) were better predicted by baseline non-HDLc and HDLc levels as compared to LDLc level [17]. In the same line, a pooled post-hoc analysis of outcomes using data from four large landmark studies had underlined the limited utility of LDLc to represent the long-established cardio-metabolic lipid load in patients with diabetic dyslipidaemia [18]. In a recent review by Ramjee et al., non-HDLc have been stated to be twice as good as LDLc in predicting risk reduction, and to demonstrate dose-dependent effects in predictive models of CVD more consistently than LDLC [19].

Additionally, a recent article concluded that even nonfasting mild-to-moderate hypertriglyceridemia from $177 \mathrm{mg} / \mathrm{dL}(2 \mathrm{mmol} / \mathrm{L})$ and above is associated with a high risk of acute pancreatitis, with hazard ratio estimates higher than that for myocardial infarction [20]. Triglycerides are predominantly carried in TG-rich lipoproteins (chylomicrons carries exogenous TG and VLDL carries endogenous TG) remnants [14], and it is the cholesterol content of these TG-rich lipoproteins that is mainly believed to lead to atherosclerosis. A study demonstrated that a $1 \mathrm{mmol} / \mathrm{L}(39 \mathrm{mg} / \mathrm{dL})$ increase in non-fasting remnant cholesterol is associated with a 2.8- 


\section{Diabetes and Obesity International Journal}

fold increase in the risk of ischaemic heart disease [8]. These elevated levels of TG-rich lipoproteins and their remnants have been shown to be linked to accumulation of intimal cholesterol, plaque formation and progression [21]. TG-rich lipoprotein remnants are also hypothesized to contribute to the progression of atherosclerosis by indirect mechanisms such as impaired vasodilation and increased inflammation [21-25].

The results from 22 year follow-up of the Bezafibrate Infarction Prevention (BIP) study and registry showed that increased levels of serum triglycerides in patients with established CHD are associated with a long-term mortality risk which is independent of HDL-C levels. The results also detected the higher risk of mortality even in subjects with triglycerides $>100 \mathrm{mg} / \mathrm{dL}$. Severe hypertriglyceridemia (triglycerides $>500 \mathrm{mg} / \mathrm{dL}$ ) was found to be associated with $68 \%$ increase in the risk of mortality over 22-years follow-up [26].

The results of Strong Heart Study also established the association between high triglyceride and increased risk of CHD. Total 3,216 American Indians participants (free of cardiovascular disease at baseline) participated in this study with a median follow-up of 17.7 years. 41\% participants were having diabetes. Participants with diabetes and high TG $(\geq 150 \mathrm{mg} / \mathrm{dL})$ plus low HDL $(<40$ $\mathrm{mg} / \mathrm{dL}$ for men and $<50 \mathrm{mg} / \mathrm{dL}$ for women) levels had a 1.54-fold greater HR (95\% CI1.15-2.06) for CHD than those with diabetes having normal TG and HDL levels. The HR for stroke was 2.13 fold greater in diabetes with high TG and low HDL compared to diabetes subjects with normal TG and HDL values [27].

Therefore, the management of hypertriglyceridaemia is important not just in the prevention of pancreatitis, but also in reducing the risk of CVD in patients with mild to moderate hypertriglyceridaemia. In a recent study the authors quoted "Numerous studies consistently showed that pharmacological interventions that target the dyslipidemia and hypertension associated with T2DM, reduce risk of macrovascular complications in such patients" [28].

Lifestyle modification in the form of diet and exercise can be considered vital to start with. However, lifestyle interventions alone are often insufficient to achieve the strict lipid goals. The addition of niacin, fibrates, or longchain omega-3-fatty acids to statin therapy has been advocated for those patients who have failed to attain normal TG levels [29-33]. However, these agents have been found to differ substantially in their TG lowering effects and they are also burdened by their gamut of side effects. Attempts to reduce TG levels, with addition of fibrates in specific patients' subgroups, have shown modest benefit. In a recently published article of 9.7 years follow-up data of the Action to Control Cardiovascular Risk in Diabetes Lipid Study (ACCORD Lipid Arm), fenofibrate therapy when added to statins was found to reduce the hazards of CVD by 27 percentage points (HR, 0.73 ; $95 \% \mathrm{CI}, 0.56-0.95$ ) in subjects with triglyceride levels greater than $204 \mathrm{mg} / \mathrm{dL}$ and high-density lipoprotein cholesterol levels less than $34 \mathrm{mg} / \mathrm{dL}$. This post-trial finding demonstrates that fenofibrate can reduce cardiovascular disease risk in this subgroup of statin-treated patients with type 2 diabetes [34].

Saroglitazar is a dual PPAR $\alpha$ and $\gamma$ agonist approved in India for the treatment of hypertriglyceridaemia in T2DM uncontrolled with statin therapy. A phase 3, controlled clinical trial has shown that saroglitazar $4 \mathrm{mg}$ once daily, when added to statin, leads to significant decrease in triglyceride (46.7\%) and non HDLc (32.5\%). In another phase 3 controlled clinical trial use of saroglitazar $4 \mathrm{mg}$ once in patients with diabetic dyslipidemia, daily for 24 weeks' treatment resulted in significant decrease in $\mathrm{HbA1c}(0.3 \%)$ in addition to lowering of lipid parameters. In these controlled clinical trials, saroglitazar was found to be safe and well tolerated. Saroglitazar was not associated with weight gain, hepatotoxicity, renal toxicity or muscle related toxicity when co-prescribed with statin $[11,12]$.

In an open label randomized study conducted in India, saroglitazarwas evaluated against fibrates as an add on therapy to metformin in diabetic dyslipidemia, saroglitazar was found to cause statistical significant reduction not only in triglycerides levels but also in all the glycemic parameters viz. FPG, PPPG and HbA1c [35].

A post-marketing, observational, multicenter, single arm study was conducted in India involving patients (2804 patients) of diabetic dyslipidemia. At 3 months follow-up, saroglitazar $4 \mathrm{mg}$ led to significant reduction in TG (35.8\%), LDLc (16.4\%), total cholesterol (19\%) and non-HDLc (23.4\%). Addition of saroglitazar to baseline anti-diabetic medications showed a significant $0.9 \%$ absolute reduction in $\mathrm{HbA1c}$ with no serious adverse events reported. This study reiterated the potent lipid lowering and anti-hyperglycaemic effects of Saroglitazar in alignment with the above trial results [36]. 


\section{Diabetes and Obesity International Journal}

A part of this study was earlier published with followup data of only 34 patients for a period of 14 weeks. The present study is a continuation to the above, with 158 patients with a follow-up period of 58 weeks showing similar reductions in glycemic and lipid parameters. We had also noticed, in our earlier studies, favorable effects on serum ALT level and no significant change in serum creatinine level following therapy with saroglitazar. Though, our earlier observations had shown a trend towards slight but insignificant change (gain) in weight, in this study with much longer duration, the weight-gain has reached a level of statistical significance. However, it should be noted that many patients were on sulfonylureas and/or insulin; hence the weight-gain cannot be solely attributable to saroglitazar alone $[13,37,38]$.

\section{Conclusion}

Raised TG levels are an inherent part of diabetic dyslipidaemia and considered independent risk factor for CVD. Current international guidelines recommend treatment of TG>200 mg/dl if not controlled by intensive statin therapy. The use of dual PPAR alpha/gamma agonist, saroglitazar, for a period of 58 weeks, was associated with significant improvement in both glycaemic and lipid parameters among Indian patients with diabetic dyslipidaemia. Overall saroglitazar was well tolerated and there was no serious adverse event reported.

\section{Limitations and Strength of this study}

The study has many limitations and the results should be interpreted in view of the limitations. As with any observational study, this study lacks the vigilance of a controlled environment and adverse events are under reported. Larger and more comprehensive trials are required to establish and further validate our findings.

Secondly, the sample size is small. The number of patients studied is 158 which is a relatively small group.

The strength of this study lies being a real world observational study with longest duration so far on record and this adds to the present body of medical literature on the usage of saroglitazar therapy where the long term data of this medication usage is only up to 24 weeks.

\section{References}

1. Kannel WB (1985) Lipids, diabetes, and coronary heart disease: insights from the Framingham study. Am Heart J 110(5): 1100-1107.

2. Jacobs MJ, Kleisli T, Pio JR, Malik S, L'Italien GJ, et al. (2005) Prevalence and control of dyslipidaemia among persons with diabetes in the United States. Diabetes Res ClinPract 70(3): 263-269.

3. (1997) UK, Prospective Diabetes Study 27. Plasma lipids and lipoproteins at diagnosis of NIDDM by age and sex. Diabetes Care 20(11): 1683-1687.

4. Taskinen MR, Borén J (2015) New insights into the pathophysiology of dyslipidaemia in type 2 diabetes. Atherosclerosis 239(2): 483-495.

5. Cholesterol Treatment Trialists (CTT) Collaborators, Kearney PM, Blackwell L, Collins R, Keech A, et al. (2008) Efficacy of cholesterol-lowering therapy in 18,686 people with diabetes in 14 randomised trials of statins: a meta-analysis. Lancet 371(9607): 117125.

6. Do R, Willer CJ, Schmidt EM, Sengupta S, Gao C, et al. (2013) Common variants associated with plasma triglycerides and risk for coronary artery disease. Nat Genet 45(11): 1345-1352.

7. Nordestgaard BG, Benn M, Schnohr P, TybjaergHansen A (2007) Non-fasting triglycerides and risk of myocardial infarction, ischemic heart disease, and death in men and women. JAMA 298(3): 299-308.

8. Varbo A, Benn M, Tybjærg-Hansen A, Jorgensen $A B$, Frikke-Schmidt R, et al. (2013) Remnant cholesterol as a causal risk factor for ischemic heart disease. J Am Coll Cardiol 61(4): 427-436.

9. Brunzell JD, Schrott HG (1973) The interaction of familial and secondary causes of hypertriglyceridemia: role in pancreatitis. Trans Assoc Am Physicians 86: 245-254.

10. Catapano AL, Graham I, De Backer G, Wiklund O, Chapman MJ, et al. (2016) 2016 ESC/EAS Guidelines for the Management of Dyslipidaemias. Eur Heart J 37(39): 2999-3058. 


\section{Diabetes and Obesity International Journal}

11. Pai V, Paneerselvam A, Mukhopadhyay S, Bhansali A, Kamath D, et al. (2014) Multicenter, Prospective, Randomized, Double-blind Study to Evaluate the Safety and Efficacy of Saroglitazar 2 and $4 \mathrm{mg}$ Compared to Pioglitazone $45 \mathrm{mg}$ in Diabetic Dyslipidemia (PRESS V). J Diabetes Sci Technol 8(1): 132-141.

12. Jani RH, Pai V, Jha P, Jariwala G, Mukhopadhyay S, et al. (2014) A multicenter, prospective, randomized, double-blind study to evaluate the safety and efficacy of Saroglitazar 2 and $4 \mathrm{mg}$ compared with placebo in type 2 diabetes mellitus patients having hypertriglyceridemia not controlled with atorvastatin therapy (PRESS VI). Diabetes Technol Ther 16(2): 6371.

13. Chatterjee S, Majumder A, Ray S (2015) Observational Study of Effects of Saroglitazar on Glycaemic and Lipid Parameters on Indian Patients with Type 2 Diabetes. Sci Rep 5: 7706.

14. Toth PP (2016) Triglyceride-rich lipoproteins as a causal factor for cardiovascular disease. Vasc Health Risk Manag 12: 171-183.

15. Brunzell JD, Schrott HG (2012) The interaction of familial and secondary causes of hypertriglyceridemia: role in pancreatitis. J Clin Lipidol 6(5): 409-412.

16. Garber AJ, Abrahamson MJ, Barzilay JI, Blonde L, Bloomgarden ZT, et al. (2017) Consensus Statement by the American Association of Clinical Endocrinologists and American College of Endocrinology on the Comprehensive Type 2 Diabetes Management Algorithm - 2017 Executive Summary. Endocr Pract 23(2): 207-238.

17. Cui Y, Blumenthal RS, Flaws JA, Whiteman MK, Langenberg P, et al. (2001) Non-high-density lipoprotein cholesterol level as a predictor of cardiovascular disease mortality. Arch Intern Med 161(11): 1413-1419.

18. Liu J, Sempos C, Donahue RP, Dorn J, Trevisan M, et al. (2005) Joint distribution of non-HDL and LDL cholesterol and coronary heart disease risk prediction among individuals with and without diabetes. Diabetes Care 28(8): 1916-1921.
19. Ramjee V, Sperling LS, Jacobson TA (2011) Non-highdensity lipoprotein cholesterol versus apolipoprotein $\mathrm{B}$ in cardiovascular risk stratification: do the math. J Am Coll Cardiol 58(5): 457-463.

20. Pedersen SB, Langsted A, Nordestgaard BG (2016) Non fasting Mild-to-Moderate Hypertriglyceridemia and Risk of Acute Pancreatitis. JAMA Intern Med 176(12): 1834-1842.

21. Chapman MJ, Ginsberg HN, Amarenco P, Andreotti F, Borén J, et al. (2011) Triglyceride-rich lipoproteins and high-density lipoprotein cholesterol in patients at high risk of cardiovascular disease: evidence and guidance for management. Eur Heart J 32(11): 13451361.

22. Alaupovic P, Mack WJ, Knight-Gibson C, Hodis HN (1997) The role of triglyceride-rich lipoprotein families in the progression of atherosclerotic lesions as determined by sequential coronary angiography from a controlled clinical trial. Arterioscler Thromb Vasc Biol 17(4): 715-722.

23. Zheng XY, Liu L (2007) Remnant-like lipoprotein particles impair endothelial function: direct and indirect effects on nitric oxide synthase. J Lipid Res 48(8): 1673-1680.

24. Wang L, Gill R, Pedersen TL, Higgins LJ, Newman JW, et al. (2009) Triglyceride-rich lipoprotein lipolysis releases neutral and oxidized FFAs that induce endothelial cell inflammation. J Lipid Res 50(2): 204213.

25. Ting HJ, Stice JP, Schaff UY, Hui DY, Rutledge JC, et al. (2007) Triglyceride-rich lipoproteins prime aortic endothelium for an enhanced inflammatory response to tumor necrosis factor-alpha. Circ Res 100(3): 381390.

26. Klempfner R, Erez A, Sagit BZ, Goldenberg I, Fisman E, et al. (2016) Elevated Triglyceride Level Is Independently Associated With Increased All-Cause Mortality in Patients With Established Coronary Heart Disease Twenty-Two-Year Follow-Up of the Bezafibrate Infarction Prevention Study and Registry. Circ Cardiovasc Qual Outcomes 9(2): 100-108.

27. Lee JS, Chang PY, Zhang Y, Kizer JR, Best LG, et al. (2017) Triglyceride and HDL-C Dyslipidemia and Risks of Coronary Heart Disease and Ischemic Stroke 


\section{Diabetes and Obesity International Journal}

by Glycemic Dysregulations Status. The Strong Heart Study. Diabetes Care 40(4): 529-537.

28. Majumder A, Chatterjee S (2014) Diabetic Dyslipidemia-Role of Saroglitazar. Med chem 4: 684687.

29. Ginsberg HN (2002) New perspectives on atherogenesis: role of abnormal triglyceride-rich lipoprotein metabolism. Circulation 106(16): 21372142.

30. Berglund L, Brunzell JD, Goldberg AC, Goldberg IJ, Sacks F, et al. (2012) Evaluation and treatment of hypertriglyceridemia: an Endocrine Society clinical practice guideline. J Clin Endocrinol Metab 97(9): 2969-2989.

31. Jellinger PS, Smith DA, Mehta AE, Ganda O, Handelsman Y, et al. (2012) American Association of Clinical Endocrinologists' guidelines for management of dyslipidemia and prevention of atherosclerosis. Endocr Pract 18(S1): 1-78.

32. Hegele RA, Ginsberg HN, Chapman MJ, Nordestgaard BG, Kuivenhoven JA, et al. (2014) The polygenic nature of hypertriglyceridaemia: implications for definition, diagnosis, and management. Lancet Diabetes Endocrinol 2(8): 655-666.

33. Jacobson TA, Ito MK, Maki KC, Orringer CE, Bays HE, et al. (2014) National Lipid Association recommendations for patient-centered management of dyslipidemia: part 1-executive summary. J Clin Lipidol 8(5): 473-488.

34. Elam MB, Ginsberg HN, Lovato LC, Corson M, Largay J, et al. (2017) Association of Fenofibrate Therapy with Long-term Cardiovascular Risk in Statin-Treated Patients with Type 2 Diabetes. JAMA Cardiol 2(4): 370-380.

35. Ghosh A, Sahana PK, Das C, Mandal A, Sengupta N (2016) Comparison of Effectiveness and Safety of Add-on Therapy of Saroglitazar and Fenofibrate with Metformin in Indian Patients with Diabetic Dyslipidaemia. J Clin Diagn Res 10(3): FC01-FC04.

36. Shetty SR, Kumar S, Mathur RP, Sharma KH, Jaiswal AD (2015) Observational study to evaluate the safety and efficacy of saroglitazar in Indian diabetic dyslipidemia patients. Indian heart journal 67(1): 2326.

37. Chatterjee S, Majumder A, Jaiswal AD (2015) Effect of Saroglitazar, a Dual PPAR- $\alpha / \gamma$ agonist, on Lipid and Glycemic Parameters in Indian Patients with Diabetic Dyslipidemia-A 27-Week, Retrospective Analysis. Diabetes 64: A101-A187.

38. Chatterjee S, Majumder A, Ray S (2016) Effect of Saroglitazar on Metabolic Parameters in Indian Patients with Diabetic Dyslipidemia: A 40-Week, Retrospective Analysis. Diabetes 65: A541-A556. 